\title{
"E teve compaixão deles (Mc 6,34)" A novidade da caracterização de Jesus como Messias compassivo em Mc
}

\author{
"And he felt compassion for them (Mk 6,34)" \\ The newness of the characterization of Jesus as the \\ compassionate Messiah in Mk
}

Heitor Carlos Santos Utrini

\section{Resumo}

O Segundo Evangelho tem como escopo principal responder o problema da identidade de Jesus. Seus ensinamentos e milagres visam revelar sua pessoa enquanto Messias. Contudo, em certos momentos da narrativa, esse objetivo é ainda mais evidente. É o que se depreende da chamada "seção dos pães" $(6,6 \mathrm{~b}-8,30)$. O tipo de Cristo que Marcos apresenta é aquele que se deixa atingir pelos sofrimentos alheios, que experimenta os dramas dos mais necessitados. Diferentemente das expectativas judaicas que ansiavam por um Messias poderoso, Mc retrata um Ungido que se sente, de certa, forma, atraído pelas mazelas humanas. O artigo faz uma análise do verbo $\sigma \pi \lambda \alpha \gamma \chi \nu i \zeta o \mu \alpha \iota$ no contexto das duas multiplicações dos pães. $\mathrm{O}$ vocábulo, longe de ser uma caracterização meramente afetiva de Jesus, oferece pistas para a compreensão do destino do Filho do Homem na segunda parte do evangelho.

Palavras-chave: Exegese do NT; Evangelhos Sinóticos; Teologia Bíblica; Cristologia. 


\begin{abstract}
The main purpose of the Second Gospel is to offer an answer to the issue concerning Jesus identity. His teachings and miracles aim to reveal his own person as the Messiah. Moreover, at certain points of the narrative, this objective becomes even clearer. Such objective may be grasped from the so-called "The Bread Section $(6,6 b-8,30)$. The type of Christ presented by Mark is one who keeps open to truly be reached by others sufferings as well as one who experiments the issues of the ones in need. Other than the Judaic expectations which were eager to having a powerful Messiah, Mark depicts an Anointed one who, somehow, feels drawn by the human pains. The article performs an analysis concerning the verb $\sigma \pi \lambda \alpha \gamma \chi \nu i \zeta o \mu \alpha \iota$ within the context of the two multiplications of bread. Such word hereby used, may not be misunderstood as a mere characterization of Jesus affection, for it offers clues to comprehend the fate of the Son of the Lord in the second part of the Gospel.
\end{abstract}

Keywords: Exegesis of the NT; Synoptic Gospels, Biblical Theology; Christology.

\title{
Introdução
}

Quando consideramos o verbo $\sigma \pi \lambda \alpha \gamma \chi \nu i \zeta o \mu \alpha \iota$ na literatura sinótica, descobrimos que ele é aplicado exclusivamente a Jesus ou a personagens que refletem o agir divino. $\mathrm{O}$ vocábulo ocorre em dois contextos distintos: primeiramente, nas narrativas de milagres onde a intervenção de Jesus é capaz de projetar nova luz nos dramas humanos (cf. Mt 20,29-34; Lc 7,11-17); em segundo lugar, nas parábolas, onde certos personagens encarnam o comportamento de Deus (cf. Mt 18,23-35; Lc 10,30-37; 15,11-12).

No evangelho de Marcos, a palavra aparece em quatro momentos. Em 1,40-45, por ocasião da cura do leproso, o leitor já sofre um primeiro impacto, pois o autor apresenta, numa mesma passagem, um Messias que se compadece diante da impureza. ${ }^{1}$ Um outro texto é Mc 9,14-29 se relata a cura de um

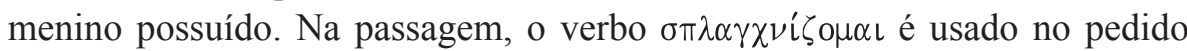
feito pelo pai do garoto (v. 22b). Depois de titubear na fé ("se podes...”), o homem apela para a compaixão de Jesus e é atendido. Assim, apesar de em

\footnotetext{
${ }^{1}$ No AT os textos que tratam da pureza/impureza são marcados pela aversão a tudo o que era impuro (cf. Lv 5,2-3; 7,20-21). Vide M. López VillanueVA, “Tocar al leproso: Mc 1,40-45. Una aproximación al ministerio de la compasión”, Estudios Eclesiasticos 77 (2002) 126.
} 
muitos milagres a fé em Jesus ser condição de possibilidade para a intervenção divina, a fé imperfeita ou a falta de fé não é obstáculo para a manifestação da compaixão do Senhor.

Há ainda outras duas ocorrências do verbo em Mc estreitamente relacionadas. Elas se encontram em Mc 6,34 e 8,2 na primeira e segunda multiplicação dos pães. A presença do vocábulo nesses dois momentos específicos do evangelho apontam para uma intenção precisa do autor em caracterizar Jesus como um Messias compassivo.

\section{A seção dos pães no contexto de todo o evangelho}

Diversos autores consideram que Mc 6,6b-8,30 constitua uma unidade literária chamada "seção dos pães". ${ }^{2} \mathrm{O}$ bloco recebe este nome porque a maioria das perícopes aí contidas fala de pão ou pães, uma palavra pouco frequente no restante do evangelho. Antes da seção dos pães, o vocábulo aparece somente em 2,26 e 3,30, enquanto que nesta parte do evangelho ocorre 18 vezes $(6,8.37 .38 .41$ [bis]. 44.52; 7,2.5.27; 8,4.5.6.14 [bis]. 16.17.19). Depois, a palavra reaparecerá somente em 14,22 por ocasião da última ceia.

Destacam-se aqui duas sequências de passagens em duplicata (6,30-7,37 e 8,1-26) que seriam compostas, primeiramente, por um milagre de multiplicação de pães (cf. Mc 6,30-44 e 8,1-10), seguido de um episódio no mar (6,45-52 e 8,13-21) e milagres de cura (6,53-56 e 8,22-26). Cada uma das duplicadas constituiria uma única ação dramática. É o que se depreende da retomada do milagre dos pães descrito em 6,35-44 no final da caminhada sobre as águas, ao dizer que os discípulos "não tinham entendido a respeito

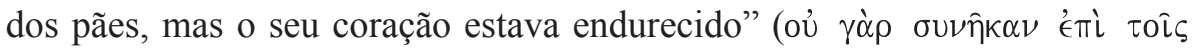

\footnotetext{
${ }^{2}$ É o que se verifica em R. M. Fowler, Loaves and fishes: The function of the feeding stories in the Gospel of Mark, Chico, Scholar Press, 1981, pp. 91-128; J. A. Grassi, Loaves and Fishes: the Gospel feeding Narratives, Collegeville, The Liturgical Press, 1991, p. 29; S. MAsudA, "The Good News of the Miracle of the Bread. The tradition and its markan redaction", New Testament Studies 28 (1982) 212-214; N. CASAlini, Introduzione a Marco, Jerusalem, Franciscan Printing Press, 2005, p. 40; G. van Oyen. The interpretation of the feeding miracles in the Gospel of Mark, Brussel, Koninklijke Academie België, 1999, p. 188; dentre outros. Contudo, a delimitação da perícope geralmente vai de $6,6 \mathrm{~b}$ a 8,26 . O texto seguirá a sugestão de J.-F. BAUDOZ, para quem a seção dos pães deveria englobar também a confissão de fé de Pedro (8,27-30) (cf. "Le repas du Seigneur d'après la section des pains en Marc [Mc 6,6b-8,30]", in J. F. Quesnell - Y.-M. Blanchard - C. Tassin. [edd.] Nourriture et repas dans les milieux Juifs et Chrétiens de l'Antiquité. Mélanges offerts à professeur C. Perrot, Paris, Cerf, 1999, pp. 91-106). As razões para tal escolha serão mencionadas posteriormente.
} 


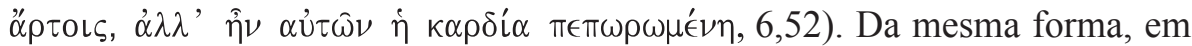
8,18-21 o autor retornará ao tema da incompreensão dos discípulos em relação às duas multiplicações de pães.

Uma vez que o evangelista apresenta o milagre da multiplicação em duplicata, deve-se perguntar sobre as motivações que levaram o autor a fazêlo. Há aqueles que defendem que a primeira multiplicação, uma vez que teria ocorrido em território judeu, estaria voltada para o povo de Israel. Por outro lado, já que a segunda multiplicação teria se dado em território pagão, os quatro mil saciados se relacionariam com os quatro pontos cardeais e os sete cestos cheios de fragmentos, com os sete diáconos de At $6 .^{3}$

Com efeito, o simbolismo numérico é bastante discutido, contudo, tentar explicar certos elementos da perícope baseando-se simplesmente nesses dados seria como caminhar num terreno pantanoso. Por mais ricos que sejam os significados e por mais interessantes que fossem as conexões, em certo sentido, o simbolismo sempre ficaria à mercê do intérprete ${ }^{4}$

\section{Caracterização messiânica de Jesus a partir da primeira multi- plicação dos pães (Mc 6,30-44)}

Imediatamente antes de realizar o primeiro milagre da multiplicação dos pães, o autor relata a tentativa frustrada de Jesus de levar seus discípulos para um lugar ermo para que pudessem descansar um pouco (6,31). Percebendo a sua intenção, as pessoas conseguem chegar ao lugar de descanso antes de Jesus. Desembarcando, tendo diante dos olhos a multidão, diz o texto que

\footnotetext{
${ }^{3}$ Para alguns autores, as duas multiplicações de pães representariam o acesso universal à ceia eucarística. Tanto judeus quanto pagãos deveriam ser acolhidos na participação da mesma (cf. E. BIANCHI, "Un pane per giudei e gentili", Parola, Spirito e Vita 7 [1979] 89-98). Há aqueles que veem inclusive no peixe um importante símbolo eucarístico no cristianismo primitivo (cf. A. Richardson, "The feeding of the five thousand: Mark 6:30-44", Interpretation 9 [1955] 146). Mas como bem recorda R. TreviJano Etcheverría, passagens como Lc 24,42-43 e Jo 21,11-14, onde o Ressuscitado come peixe com os discípulos, seu alcance é bastante discutível. Ademais, as representações de refeições cristãs onde o peixe é retratado em afrescos nas catacumbas são relativamente tardias. Dessa forma, tais autores pecam por anacronismo (cf. "Historia de milagro y Cristología en la multiplicación de los panes", Burgense 17 [1976] 12). ${ }^{4}$ Assim, o número sete é associado seja aos sete diáconos da igreja primitiva, seja as setenta nações pagãs (cf. J. R. Donahue - D. J. Harrington, "The Gospel of Mark", in D. J. Harrington [ed.], Sacra Pagina Series, 2, Collegeville, The Liturgical Press, 2002, p. 207). Enquanto alguns associam o doze às tribos de Israel, outros o associam ao número dos apóstolos (cf. B. E. THIERING, "Breaking of bread and harvest in Mark's Gospel”, Novum Testamentum 12 [1970] 3-4).
} 
Jesus "foi movido de compaixão por eles, porque eram como ovelhas que não tinham pastor, e começou a ensinar-lhes muitas coisas" (v. 34).

Em muitas ocasiões o autor apresenta o estado de ânimo de Jesus diante das necessidades dos homens. Sua ternura pode ser vista quando ele, algumas vezes, usa o apelativo «filho/filha» que indica uma profunda participação na condição daqueles que a ele se dirigem (cf. 2,5; 5,34; 10,24). Porém aqui não se trata de uma mera solidariedade afetiva de um homem por outro, mas é o sentimento do próprio Deus que o move para junto daqueles que sofrem com o intuito de salvar-lhes. ${ }^{5}$

Em 6,34 o texto nos oferece uma explicação (ö $\tau \iota)$ para o sentimento de Jesus: "eram como ovelhas que não tinham pastor" (

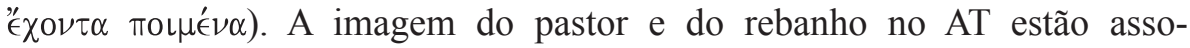
ciadas, de modo bastante profundo, ao povo de Israel. Muito embora sejam escassos os textos antigos em que Deus venha chamado de "Pastor de Israel" (cf. Gn 48,15; 49,24), ${ }^{6}$ no saltério e nos profetas, a partir do exílio, o uso do termo é acentuado (cf. S1 28,9; 74,1; 77,20; 78,52-53; 95,7; 121,4; Jr, 23,2; 31,10; Ez 34,11-12; Is 40,10-11; Mq 4,6-7). Apesar disso, são frequentes as referências em que o povo recebe a denominação de rebanho (cf. Jr 13,17; Is 40,11; Ez 34,31; Mq 7,14; Zc 10,3; S1 79,13; 95,7; 100,3). Os representantes escolhidos por Deus para estarem à frente de seu povo são associados a pastores, nem sempre zelosos e fiéis ao seu ofício (cf. 2Sm 5,2; S1 78,70-72; Is 56,$11 ; \mathrm{Jr} 2,8 ; 22,22 ; 23,1-4 ; \mathrm{Ez} 34,2-10){ }^{7}$

\footnotetext{
${ }^{5} \mathrm{cf}$. N. CASALINI, Lettura di Marco: narrativa, esegetica, teologica, Jerusalem, Franciscan Printing Press, 2005, pp. 69-70.

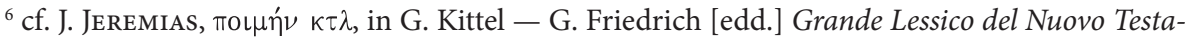
mento, X, Brescia, Paideia, 1975, p. 1197. Segundo o autor, tal apelativo era evitado porque era comum aplicá-lo às divindades orientais.

${ }^{7}$ No midrash Êxodo Rabbah 2,1 encontramos o seguinte texto: “Moisés era pastor (Ex 3,1). Está escrito: Ele dava a conhecer a Moisés seus caminhos, aos filhos de Israel suas façanhas. É YHWH compassivo e misericordioso, lento para a ira e rico em clemência (Sl 103,7) (...). O Santo, bendito seja, deu a conhecer estas qualidades a Moisés quando este lhe pediu Dá-me a conhecer, por favor, teus caminhos (Ex 33,13), e o Santo, bendito seja, lhe respondeu: Farei misericórdia a quem fizeres e serei compassivo com quem tiveres compaixão (Ex 33,19)". Como vimos, Deus comunica a Moisés-pastor seus atributos de misericórdia e compaixão. E o texto continua: "Nossos mestres disseram: quando Moisés estava apascentando o gado de Jetro no deserto, escapou-lhe um cabrito; perseguiu-o até que chegou a um cercado onde tinha casualmente uma piscina de água e o cabrito se deteve a beber. Quando Moisés chegou até ele lhe disse: «Não sabia que corrias por causa da sede. Deves estar cansado», e colocando-o sobre seus ombros, voltou. Então lhe disse o Santo, bendito seja: «Tens bons sentimentos para guiar o rebanho de um homem; assim, pois, juro-te que apascentarás meu rebanho». Daí [procede] que Moisés era pastor" (Midrash Exxodo Rabbah 2,2).
} 
Partindo dessas premissas, os conceitos "pastor/ovelhas" no AT se vinculam de modo particular ao povo da Aliança. Em Mc 6,34c, "pastor" é o próprio Jesus a se compadecer diante do sofrimento alheio e as "ovelhas" são aquela multidão composta por aproximadamente cinco mil homens (v. 44) que Jesus tem diante dos olhos, provenientes de todas as cidades (v. 33c). Tal descrição do rebanho não nos permite associá-lo a nenhum grupo étnico ou social específico, o que equivale a dizer que a compaixão de Jesus não conhece confins e atinge a todos, indistintamente. $\mathrm{O}$ grupo que procura por Jesus, que ouve suas palavras e que por ele é alimentado torna-se, dessa forma, o paradigma de todos aqueles que se aproximam do Senhor.

Consoante o v. 34, aparentemente se pode dizer que não há nenhuma conexão necessária entre a multiplicação dos pães e a compaixão experimentada por Jesus, pois a multidão não necessitava que Jesus fizesse o milagre. Os apóstolos sugerem que as pessoas sejam despedidas, exatamente porque não veem nenhum dano em tal comportamento.

Ora, se por um lado a compaixão não se relaciona de modo exclusivo com o milagre em si, há uma outra atividade de Jesus diretamente ligada a ela: «e começou

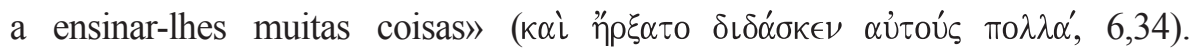
O ensinamento é, portanto, o tema central do versículo. Ora, se o autor fala frequentes vezes da atividade magisterial de Jesus que, "como de costume, de

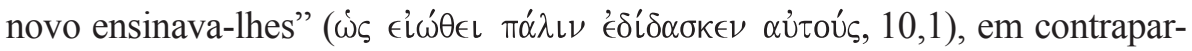
tida, ele evita falar do conteúdo do ensinamento $(1,21.22 ; 2,13 ; 6,2)^{8}$. A novidade da perícope é a associação do pastor ao tema do ensinamento 9 .

Este texto nos aproxima bastante de Mc 6,34 onde Jesus, qual pastor, se compadece da multidão que se assemelhava a um rebanho perdido (apud M. PÉrez Fernández, Textos Fuente y Contextuales de la Narrativa Evangélica. Metodología aplicada a una selección del evangelio de Marcos, Estella, Verbo Divino, 2008, pp. 437-439).

${ }^{8}$ Não obstante isso, alguns autores levantam especulações acerca do conteúdo do ensinamento de Jesus em 6,34d. Para estes autores, teria ele falado sobre o Reino dos céus (provavelmente baseando-se no texto paralelo de Lc 9,11) ou então tentado corrigir a visão incorreta das pessoas acerca de seu messianismo (cf. H. Montefiore, "Revolt in the desert?", p. 136; J. MAteos — F. Camacho, Il Vangelo di Marco, II, p. 67; R. Trevijano Etcheverría, "Crisis mesiánica en la multiplicación de los panes [Mc 6,30-46 y Jn 6,1-15]”, Burgense 16 [1974] 435). Seja como for, muito mais importante que tentar descobrir o conteúdo da pregação - coisa que nem mesmo o evangelista se preocupou em fazê-lo — é afirmar o fato de que Jesus ensina.

${ }^{9}$ Encontramos um paralelo no Midrash Números Rabbah 33,2: "Isto é o que [a Escritura] diz: 'Conduziste - נהיט - qual rebanho a teu povo pela mão de Moisés e Aarão' (S1 77,21). O que

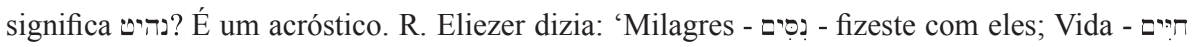
- lhes deste; o Mar - ם' - dividiste para eles; a Torah - תוזרדה - lhes deste'". Ainda na literatura 
Ao narrar a sua história, Mc não quer ser um mero colecionador de fatos a respeito de Jesus. Há indícios textuais de que o autor tinha em mente os seus leitores, portanto, um grupo real ${ }^{10}$. Assim, o material escolhido por Mc para ser narrado à comunidade deveria ter algum sentido para ela. Aqui não encontraremos todas as respostas a respeito da identidade de Jesus, de modo que o texto funciona como um quebra-cabeças no qual o leitor vai construindo, pouco a pouco, a imagem do Mestre. Contudo, pretender construir tal retrato prescindindo de sua atividade magisterial seria algo impossível na concepção marciana.

Muito embora em Mc os milagres ocupem um lugar de realce no conjunto do evangelho, quando tomados de maneira isolada eles nos oferecem uma ideia falsa a respeito de Jesus. Aos poucos o autor vai subordinando a importância dos milagres a outros elementos, como por exemplo, o fato de que Jesus deve sofrer, morrer e ressuscitar dos mortos $(8,31-32 ; 9,30-31 ; 10,32-34)^{11}$.

Ora, se a ênfase do v. 34 recai sobre o aspecto do ensinamento, qual a necessidade de se narrar logo em seguida um milagre? Mc oferece uma imagem equilibrada entre dois polos. Seja quando Jesus se põe a ensinar, seja quando realiza um milagre, em ambas as ocasiões ele está ensinando ao povo, porém de modos diferentes. As duas maneiras de pregar apontam para a sua identidade enquanto Messias. Tanto os discursos quanto os milagres são realizados com a mesma autoridade e poder. ${ }^{12}$

Jesus contempla um grupo social e espiritualmente perdido por causa da parcialidade do ensinamento dos escribas, fariseus, sacerdotes e anciãos. A reação de afeto não deve ser entendida como se fosse um parêntese na narrativa. Ao inseri-la, Mc está oferecendo aos leitores uma característica teológica que lhes permitirá um conhecimento mais adequado a respeito de Jesus. É um impulso interior, movimento visceral, íntimo e apesar de todo esforço para se tentar traduzir isso em palavras, "nem mesmo essas expressões

apócrifa temos: "Eu respondi e lhes disse: 'Os pastores, as lâmpadas e as fontes vêm da Lei; se nós nos afastamos dela, a Lei permanece. Se, pois, prestais atenção à Lei e estais atentos à sabedoria, não faltará a lâmpada, não se irá o pastor, nem a fonte se secará" " $(2 \mathrm{Br} 77,15-16)$.

${ }_{10}$ Alguns desses indícios são evidentes, como o aparte de 13,14 ("que o leitor entenda",

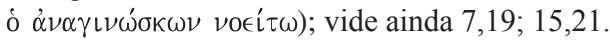

${ }^{11}$ cf. P. J. Achtemeier, "He taught them many things. Reflections on Marcan Christology", Catholic Biblical Quarterly 42 (1980) 476. J. GnilKa, El Evangelio según San Marcos, I, Salamanca, Sígueme, 1999, p. 302.

12 "In sum, the Jesus that Mark is intent on portraying is a Jesus who performed mighty acts, but not as a sheer magician or miracle-worker. The Jesus who performed mighty acts is the Jesus who was preeminently the teacher, and whose power as teacher is made visible in the acts of power he regularly performed": P. J. ACHTEMEIER, “He taught them many things", p. 478. 
conseguem captar o profundo sabor físico e emocional da palavra grega para compaixão"13. Diante do desorientamento do povo, Jesus prova compaixão e se põe a ensinar: com palavras e atos de poder, mas sempre ensinamento.

Ele não tem a pretensão de tentar resolver todos os problemas da multidão por meio dos milagres, aliás o texto sequer menciona a necessidade do milagre. Mais do que um simples observador externo, Jesus participa da dor e opressão do povo, estabelecendo com este uma relação estreita, abrindo-o para uma possível resposta de fé.

O retrato de Jesus enquanto Messias-Pastor se distancia, portanto, de todas as concepções messiânicas centradas na soberania da realeza ou do poderio militar - apesar de em algumas perícopes o pastor ganhar características militares e políticas (cf. Ez 34; Mq 4,6-7). A natureza do Messias é aquela da ternura do Pastor que conduz e protege o seu rebanho com desvelo, guiando-o com seu ensinamento.

Sem dúvidas, o episódio da multiplicação dos pães incidiu de maneira direta na autocompreensão de Jesus a respeito de sua messianidade. Ele encarna o ideal do pastor fiel apresentado no AT e uma vez tendo sido estabelecido tal pastor, a aliança de paz entre Deus e o rebanho será selada (cf. Ez 34,23-25). É ele quem livrará o rebanho do medo e do terror e não lhe faltará nada (cf. Jr 23,4-5). É ele quem apascentará com a força do Senhor e as ovelhas viverão em paz (cf. Mq 5,1-4).

Além do teor afetivo, o Messias aqui reproduzido se reveste de autoridade. O simples fato de ensinar já evoca a autoridade do Mestre. Portanto, o Pastor-Messias de Mc exerce o seu pastoreio com a competência de quem o faz por direito. Mas tudo isso sem se impor, sem coagir o rebanho à obediência. Tais ideias não nos permitem abarcar toda a personalidade de Jesus e construir uma cristologia exaustiva. Porém, esses elementos não poderiam ser descuidados sob pena de construirmos uma imagem que não correspondesse àquela desejada pelo autor do evangelho. A profunda humanidade de Jesus caracteriza o seu messianismo que, por sua vez, vem revestido de uma autoridade zelosa e compassiva.

\footnotetext{
${ }^{13}$ A. Nolan, Jesus antes do cristianismo, São Paulo, Paulinas, 1988, p. 49. Recorde-se que a origem do verbo $\sigma \pi \lambda \alpha \gamma \chi \nu i \zeta$ ou $\alpha \iota$ remonta ao substantivo $\sigma \pi \lambda \alpha \gamma \gamma \chi \nu \alpha$ que indica as vísceras, seja dos animais, seja do ser humano. Portanto, o verbo reflete a antiga crença de que certos sentimentos intensos - tais como a ira, a inveja, o amor — tinham a sua sede nas entranhas humanas (cf. H. Köster, $\sigma \pi \lambda \dot{\alpha} \gamma \chi 0 \nu$ $\kappa \tau \lambda$., Kittel, G. - Friedrich, G. (edd.) Grande Lessico del Nuovo Testamento, XII, Brescia, Paideia, 1979, 904-934).
} 


\section{A imagem do Messias na segunda multiplicação (Mc 8,1-10)}

Na segunda multiplicação dos pães, a compaixão de Jesus não é uma observação feita por um redator onisciente. Quis o evangelista colocar nos lábios do próprio Jesus a manifestação de seu sentimento, tornando-o assim muito mais enfático: "compadeço-me da multidão" $(8,2 a)$.

Contudo, se no primeiro caso o que motivou a manifestação da compaixão foi a desorientação do povo, de modo que Jesus oferece seu ensinamento, aqui a razão é bem outra: as pessoas não tinham o que comer. Em 6,35 diz-se que o

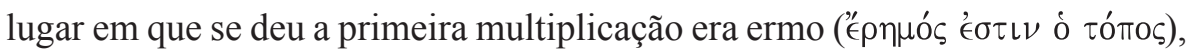
ou seja, solitário. A palavra não indica necessariamente a impossibilidade de se conseguir algo para comer, tanto que os próprios discípulos ventilam tal hipótese (v. 37).

Na segunda multiplicação o caso é mais dramático, pois eles se encon-

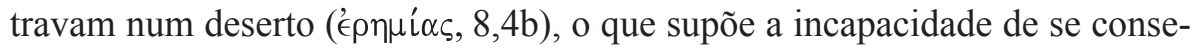
guir comida pela redondeza, como as palavras de Jesus no-lo indicam (v. 3). É nesse momento que se percebe a fineza psicológica demonstrada pelo autor. A imagem por ele pintada é aquela de um Jesus, antes de mais nada, atento. Diante da necessidade alheia, ele não se mantém indiferente. O sentimento visceral sai do universo abstrato de uma pura emoção humana e se concretiza em gestos capazes de mudar a situação das pessoas que dele necessitam.

Além disso, aquilo que Jesus tem a oferecer não se trata somente de um conforto psicológico ou de segurança doutrinária. No presente caso, preocupa-se com realidades materiais, "porque já [há] três dias permanecem comigo e não têm o que comer" (v. 2bc). Tais palavras nos permitem dizer que a vida feliz no Reino anunciado por Jesus, muito embora seja gozada em modo pleno na eternidade, desde agora seus efeitos podem ser percebidos. O cuidado de Jesus abarca todo o homem, sem qualquer visão maniqueísta da realidade, abrangendo desde as menores carências humanas, até nossos anseios mais profundos. ${ }^{14}$

\footnotetext{
${ }^{14}$ Para L. Cerfaux, Jesus se revela como o benfeitor messiânico que promete todos os bens, temporais e espirituais (cf. L. Cerfaux "La section des pains [Mc VI, 31-VIII, 26; Mt XIV, 13XVI, 12]", in P. Benoît, Synoptische Studien: Alfred Wikenhauser zum siegzigsten Geburtstag am 22. Februar 1953 dargebracht von Freunden, Kollegen und Schülern, München, Zink, 1953, p. 74).
} 


\section{A questão da identidade de Jesus}

A "seção dos pães" reflete, de modo particular, sobre um dos temas centrais de todo o evangelho, a saber, a identidade de Jesus ${ }^{15}$. Quase que a modo de refrão desponta o tema da falta de compreensão dos discípulos no sentido de perceberem a verdade acerca de sua pessoa. Aqui parece ser intenção do autor apresentar Jesus não apenas como o Messias esperado pelo povo de Israel, mas como um Messias que encarna ideais nunca antes retratados.

A pedra de toque para o entendimento das histórias de multiplicação são os diálogos entre Jesus e os discípulos logo após cada milagre. De certa forma, as duas multiplicações foram contadas em função do tema da incompreensão, conforme se depreende da interpretação oferecida depois de cada um dos episódios (cf. 6,52 e 8,14-21).

Após multiplicar os pães pela primeira vez, Mc apresenta o episódio de Jesus que caminha sobre as águas, provocando perturbação nos discípulos (cf. 6,49-50). Continuando a narrativa, o evangelista diz que, tendo Jesus embarcado, o vento cessou, enquanto que os discípulos "estavam atordoados

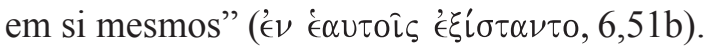

A causa da estupefação é apresentada na sentença seguinte: "de fato, não entenderam a respeito dos pães, mas o coração deles estava endurecido" $(6,52)$. Entretanto, o autor não se preocupa em apresentar o que os discípulos deveriam ter compreendido.

As palavras de 6,52 são retomadas em $8,17 \mathrm{~b}$, novamente num contexto de diálogo entre Jesus e seus discípulos, durante a travessia do lago. Esse pormenor nos leva a crer que 6,52 deva ser lido à luz de $8,14-21^{16}$. Se prescindirmos do v. 15, o problema dos primeiros versículos gira ao redor da pouca quantidade de pão que os discípulos dispunham.

Em 8,14 diz o autor que os Doze se esqueceram das provisões, tendo apenas um único pão consigo. A seguir, Jesus faz uma grave advertência aos seus discípulos: "guardai-vos do fermento dos fariseus e do fermento de Herodes!"

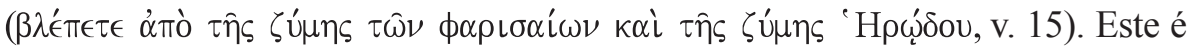
o único versículo onde aparece a palavra $\zeta$ ú $\mu$ em todo o evangelho.

\footnotetext{
${ }^{15}$ Nesse ponto, concordam G. van Oyen, The Interpretation of the Feeding Miracles in the Gospel of Mark, p. 191; J.-F. BAudoz, "Le repas du Seigneur d'après la section des pains en Marc", p. 92; K. P. Donfried, "The feeding narratives and the Marcan community (Mark 6,30-45 and 8,1-10)”, in D. Lührmann - G. Strecker (edd.), Kirche: Festschrift für Günther Bornkamm zum 75 Geburtstag, Tübingen, J. C. B. Mohr, 1980, pp. 101-102; J. GnILKA, El Evangelio según San Marcos, II, Salamanca, Sígueme, 2001, p. 355.

${ }^{16} \mathrm{cf}$. G. van Oyen, The Interpretation of the Feeding Miracles in the Gospel of Mark, p. 191.
} 
No texto imediatamente anterior à primeira multiplicação, aparece a figura de Herodes que discute a respeito da verdadeira identidade de Jesus. As opiniões apontam para três personagens: uns dizem que é João Batista, outros que é Elias e outros ainda afirmam se tratar de um dos profetas $(6,14-15)$. Essas três figuras serão novamente citadas por ocasião da confissão de fé de Pedro em Cesareia de Filipe (8,27-30), de modo que os dois textos se iluminam. ${ }^{17}$

Em ambos é exigida uma resposta pessoal; nos dois casos, Jesus seria João Batista, Elias ou um dos profetas. Contudo, Herodes responde por ouvir dizer, em terceira pessoa, sem se preocupar em conhecer verdadeiramente Jesus. Para ele, trata-se de João Batista redivivo $(6,16)$. Já Pedro, em segunda pessoa, responde a partir de sua experiência com o Senhor $(8,29)$. É a passagem de uma resposta confusa sobre a pessoa de Jesus para a descoberta de sua verdadeira identidade, mesmo que ainda parcial. ${ }^{18}$

No que diz respeito aos fariseus, após a segunda multiplicação, o evangelista narra a sua discussão com Jesus, exigindo deste um sinal vindo do céu $(8,11)$. Tal

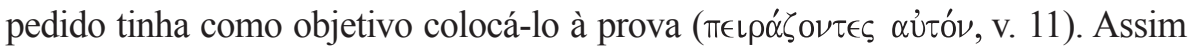
sendo, o fermento dos fariseus e de Herodes poderia se tratar da superficialidade e do fechamento obstinado no intuito de descobrirem a real identidade de Jesus, ou seja, é expressão de sua má-vontade em acreditar ${ }^{19}$.

Os discípulos, por sua vez, parecem ter entendido o termo $\zeta$ ú ${ }_{\eta}$ de modo literal, pois em 8,16 preocupam-se com o fato de não terem pão. Curioso é perceber que tanto a dureza dos fariseus quanto a lentidão dos discípulos são descritas do mesmo modo. ${ }^{20}$

${ }^{17}$ cf. J.-F. BAUdoz, «Le repas du Seigneur d'après la section des pains en Marc», 92-94.

${ }^{18}$ cf. J.-F. BAudoz, art. cit., 92-93. Este autor inclui a confissão de fé de Pedro na seção dos pães por considerar que a perícope sintetiza as perguntas referentes à identidade de Jesus até então dispersas na primeira parte. Dessa forma, Baudoz divide a seção dos pães em um quadro introdutório (6,6b-29), no corpo da seção $(6,30-8,26)$ e na conclusão (8,27-30) (pp. 93-94).

${ }^{19} \mathrm{cf}$. G. van Oyen, The Interpretation of the Feeding Miracles in the Gospel of Mark, p. 197. O texto paralelo de Mt 16,5-12 oferece uma interpretação a respeito do que se tratava o fermento dos fariseus e dos saduceus. Segundo este evangelista, trata-se "da doutrina dos fariseus e sadu-

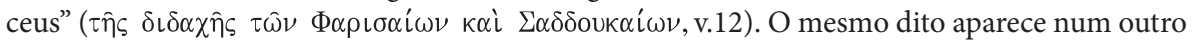
contexto em Lc 12,1, mas, segundo este evangelista, o fermento dos fariseus de que os discípulos

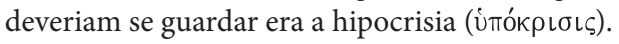

${ }^{20}$ No contexto das questões disputadas entre Jesus e os fariseus apresentadas no início de seu evangelho, Mc narra a cura de um homem com a mão seca, em pleno dia de sábado, na sinagoga. Os fariseus observavam Jesus para ver se este realizaria a cura em dia de sábado $(3,2)$. Depois que Jesus lhes pergunta se era permitido fazer o bem ou o mal no sábado, tendo estes

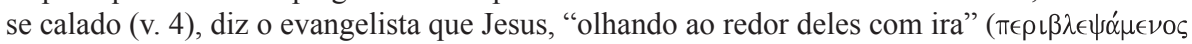

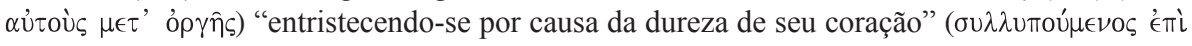


A imagem dos discípulos que emerge de 8,17-21 não é radicalmente negativa. Muito embora se lembrem das duas multiplicações dos pães - o que nos permite dizer que nem tudo está perdido - não compreendem o sentido

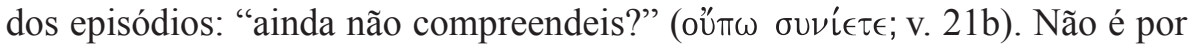
acaso que o episódio seguinte trata-se da cura de um cego em Betsaida (vv. 22-26) e, depois dessa cura, Mc insere a confissão de fé de Pedro (vv. 27-30). ${ }^{21}$

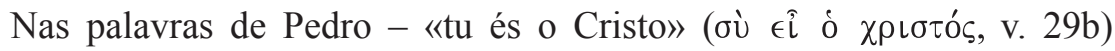
- vemos que finalmente os discípulos começam a entender alguma coisa a respeito da identidade de Jesus. Todavia esse conhecimento deverá ser aprofundado mediante as predições da paixão $(8,31-33 ; 9,30-32 ; 10,32-34)$ que, de certa forma, apontam para a manifestação do Filho do Homem no mistério da cruz (cf. 15,39).

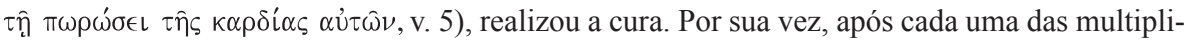
cações dos pães, diante da incapacidade dos discípulos de entenderem os milagres realizados, Jesus utilizará praticamente a mesma terminologia. Em 6,52, ao final da caminhada sobre as águas, Mc diz que os discípulos não tinham entendido o episódio dos pães porque "seu coração

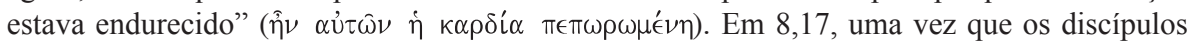
estivessem preocupados com a quantidade de pão, Jesus lhes pergunta: "tendes o vosso coração

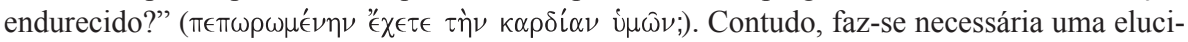
dação acerca da terminologia. Se, por um lado, a expressão "coração endurecido" referindo-se aos fariseus diz respeito à sua contumácia em rejeitar a pessoa de Jesus, por outro, a mesma expressão, aplicada aos discípulos, aponta para sua falta de fé e, portanto, para a incapacidade de compreender o real sentido dos acontecimentos. Nesse caso, a dureza de coração implica a sua estupidez e ignorância.

${ }^{21}$ Nesse sentido, D. F. Robinson questiona se a insistência em apresentar a dureza de coração dos discípulos seria uma caracterização dos mesmos ou um expediente literário, que teria como objetivo chamar a atenção dos leitores para mergulharem no sentido dos acontecimentos (cf. "The parable of the loaves", Anglican Theological Review 39 [1957] 111). Digno de nota é ainda o trabalho de G. VAN OYEN que, comentando a respeito das perícopes da multiplicação, dedica particular interesse ao problema da má compreensão acerca do discipulado. Em sua obra, critica a visão unilateral daqueles exegetas que ressaltavam somente os aspectos negativos do grupo dos Doze e se esqueciam dos inúmeros pontos positivos. Oferece cinco razões pelas quais a crítica aos discípulos, apesar de todas as sombras, deve ser mitigada: 1) há inúmeras passagens positivas que não podem ser desconsideradas; 2) os textos deixam transparecer que os verdadeiros oponentes de Jesus são os fariseus e não os discípulos; 3) se a incompreensão dos discípulos gira em torno de sua falsa compreensão cristológica, então os textos sobre o discipulado são, em última análise, textos sobre Jesus. Ora, por mais conectados que estejam os temas, a ênfase em Mc recai sobre a pessoa de Jesus; 4) mesmo em 8,14-21 há aspectos positivos que não podem ser descartados. A resposta correta dada por eles nos vv. 19-20 abre uma perspectiva para uma melhor compreensão dos fatos; e, por fim 5) uma vez que nos textos o leitor é chamado a se identificar com os discípulos e a fazer sua experiência de fé, o retrato dos mesmos não deveria ser excessivamente negativo, a ponto dessa identificação ficar comprometida (cf. The Interpretation of the Feeding Miracles in the Gospel of Mark, pp. 202-204). 
Assim sendo, a incompreensão dos discípulos faria também parte do chamado "segredo messiânico», um expediente literário por meio do qual Jesus se dá a conhecer aos poucos, através de seus milagres, mas também em sua paixão, morte e ressurreição. Tanto para a compreensão dos milagres, quanto para a aceitação de sua cruz e ressurreição, a fé é condição de possibilidade para um real conhecimento de sua pessoa.

\section{Jesus, o Messias compassivo}

Se era a intenção de Mc, na seção dos pães, propor uma reflexão acerca da identidade de Jesus, bem como caracterizá-lo como compassivo, faz-se mister encontrar a relação entre os dois tópicos. Foi dito que a compaixão de Jesus não era a descrição de um mero sentimento humano, mas funciona como que uma caracterização messiânica.

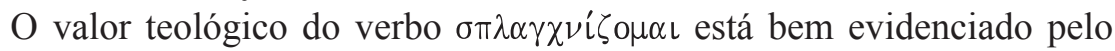
fato de ele, na literatura sinótica, ter sempre a Deus como sujeito ou então, certos personagens que representam o seu modo de agir. No caso específico de Marcos, refere-se exclusivamente à pessoa de Jesus.

$\mathrm{Na}$ seção dos pães o mistério acerca da pessoa de Jesus vai sendo, aos poucos, esclarecido a partir de seus gestos de poder e de sua missão de ensinar. Com efeito, ele é o Messias, mas realiza esse ideal de modo um pouco diferente do que até então se esperava. A seção culmina com a confissão de fé de Pedro, que se desdobra nos anúncios da paixão. Dessa forma, Jesus é, com efeito, o Messias esperado, porém, tal messianismo se concretiza na aceitação voluntária do sofrimento. Sua identidade será plenamente revelada no momento de sua cruz e ressurreição.

Ora, se Jesus é o Cristo que se revela na cruz, é justamente por causa de sua compaixão que ele assume o destino do Filho do Homem e aceita a morte de cruz. Daí a necessidade de tal caracterização messiânica, pois a compaixão o levará à cruz, e só assim será possível a compreensão, da parte do homem, acerca de sua identidade.

\section{Referências Bibliográficas}

Achtemeier, J. P. "He taught them many things. Reflections on Marcan Christology", Catholic Biblical Quarterly 42 (1980) 465-481.

BAUDOZ, J.-F. "Le repas du Seigneur d'après la section des pains en Marc (Mc 6,6b-8,30)”. In: J. F. Quesnell - Y.-M. Blanchard - C. Tassin. (edd.) 
Nourriture et repas dans les milieux Juifs et Chrétiens de l'Antiquité. Mélanges offerts à professeur C. Perrot. Paris, Cerf, 1999, pp. 91-106.

Bianchi, E. “Un pane per giudei e gentili”, Parola, Spirito e Vita 7 (1979) 89-98. CAsalin, N. Introduzione a Marco. Jerusalem, Franciscan Printing Press, 2005. . Lettura di Marco: narrativa, esegetica, teologica. Jerusalem, Franciscan Printing Press, 2005.

Cerfaux, L. "La section des pains (Mc VI, 31-VIII, 26; Mt XIV, 13XVI, 12)". In: Benoît, P. Synoptische Studien: Alfred Wikenhauser zum siegzigsten Geburtstag am 22. Februar 1953 dargebracht von Freunden, Kollegen und Schülern. München, Zink, 1953, pp. 64-77.

Donahue, J. R - Harrington, D. J. “The Gospel of Mark". In: Harrington, D. J. (ed.) Sacra Pagina Series, 2. Collegeville, The Liturgical Press, 2002.

Donfried, K. P. "The feeding narratives and the Marcan community (Mark 6,30-45 and 8,1-10)". In: Lührmann, D. - Strecker, G. (edd.) Kirche: Festschrift für Günther Bornkamm zum 75 Geburtstag. Tübingen, J. C. B. Mohr, 1980, pp. 95-103.

Fowler, R. M. Loaves and fishes: The function of the feeding stories in the Gospel of Mark. Chico, Scholar Press, 1981.

GnitKa, J. El Evangelio según San Marcos, I-II. Salamanca, Sígueme, 1999-2001.

Grassi, J. A. Loaves and Fishes: the Gospel feeding Narratives. Collegeville, The Liturgical Press, 1991.

Jeremias, J. poimh,n ktl. In: Kittel, G. - Friedrich, G. (edd.) Grande Lessico del Nuovo Testamento, X. Brescia, Paideia, 1975, pp. 1193-1236.

López Villanueva, M. “Tocar al leproso: Mc 1,40-45. Una aproximación al ministerio de la compasión”, Estudios Eclesiasticos 77 (2002) 115-139.

Masuda, S. "The Good News of the Miracle of the Bread. The tradition and its markan redaction", New Testament Studies 28 (1982) 191-219.

Nolan, A. Jesus antes do cristianismo. São Paulo, Paulinas, 1988.

Pérez Fernández, M. Textos Fuente y Contextuales de la Narrativa Evangélica. Metodología aplicada a una selección del evangelio de Marcos. Estella, Verbo Divino, 2008. 
Richardson, A. "The feeding of the five thousand: Mark 6:30-44", Interpretation 9 (1955) 144-149.

Robinson, D. F. “The parable of the loaves”, Anglican Theological Review 39 (1957) 107-115.

Thiering, B. E. "Breaking of bread and harvest in Mark's Gospel”, Novum Testamentum 12 (1970) 1-12.

Trevijano Etcheverría, R. "Historia de milagro y Cristología en la multiplicación de los panes", Burgense 17 (1976) 9-38.

Trevijano Etcheverría, R. “Crisis mesiánica en la multiplicación de los panes (Mc 6,30-46 y Jn 6,1-15)”, Burgense 16 (1974) 413-439.

VAN OYEN. G. The interpretation of the feeding miracles in the Gospel of Mark. Brussel, Koninklijke Academie België, 1999.

\section{Heitor Carlos Santos Utrini}

Doutor em Teologia Bíblica pela Pont. Univ. S. Tomás de Aquino "Angelicum" - de Roma

Professor do Instituto Superior de Teologia da Arquidiocese do Rio de Janeiro Professor do Instituto de Filosofia e Teologia "Sedes Sapientiae" da Diocese de Campos - RJ

Rio de Janeiro/RJ - Brasil E-mail: hcsutrini@gmail.com

Recebida em: 01/06/13

Aprovada em: 20/09/13 